has occurred. ${ }^{34}$ Surgery is indicated for large free lower oesophageal perforations ${ }^{4}$ or complications, for example mediastinitis. ${ }^{5}$ In the case reported here, the exact level of perforation was not clear but was in the upper oesophagus, and she initially progressed satisfactorily with conservative treatment. Signs of systemic sepsis developed, with respiratory failure and cardiovascular instability. At that stage, she was thought to have developed a nosocomial pneumonia, but we were concerned that a mediastinal infection may be developing.

The sudden onset of airway obstruction was first thought to be related to problems with the tracheal tube position. After recurrence of the obstruction, it became clear that this was caused by extrinsic tracheal compression, which occurred suddenly when the extrinsic intrathoracic pressure reached a level that caused the trachea to collapse. Artificial ventilation with BIPAP, where $P_{\text {insp }}$ was constant, meant that once the extrinsic pressure exceeded the $P_{\text {insp, }}$, the ventilation became ineffective. In addition, the mediastinal abscess had probably been developing for a few days, causing some inflammation and weakening of the tracheal wall. The chest $\mathrm{x}$-ray appearances did not change during this period, and the tracheal tube was effectively stenting the upper trachea, so the possibility of sudden airway obstruction was unsuspected.

This case shows that life-threatening distal tracheal obstruction can occur suddenly, and may be undetected by serial chest $\mathrm{x}$-rays. Furthermore, the obstruction developed despite an appropriately positioned tracheal tube. Conventional teaching is that if a tracheal tube is obstructed it should be removed, but in this case, removal of the tube is likely to have made ventilation more difficult or impossible.

During the conservative management of oesophageal perforation, the threshold for performing a CT scan of the chest should be low. In this case, earlier imaging would probably have shown the mediastinal collection, and allowed drainage before the subsequent airway obstruction occurred. However, the index of suspicion was not high and although CT scanning was considered, her poor cardiorespiratory state made us reluctant to move her for a chest CT scan.

An alternative could have been regular inspection of the trachea and carina by fibreoptic bronchoscopy, although this carries risks in an unstable patient, and it is unclear at what stage early tracheal inflammation or compression would have been detectable.

We suggest that in a patient with mediastinal pathology, the possibility of airway obstruction should always be considered, even in the presence of an appropriately placed tracheal tube. Intensive care patients are very often dependent on PEEP and high $\mathrm{FI}_{\mathrm{O}_{2}}$, and investigation may be difficult. The axiom of changing a tracheal tube first in the setting of acute airway obstruction is not always safe. In this case, fibreoptic bronchoscopy was very useful to determine the cause, and plan subsequent management.

\section{References}

I Robie DK, Gursoy MH, Pokorny WJ. Mediastinal tumoursairway obstruction and management. Semin Paed Surg 1994; 3: 259-66

2 Smith CCK, Tanner NC. The complications of gastroscopy and oesophagoscopy. Br J Surg 1956; 43: 396-403

3 Shaffer HA, Valezuela G, Mittal RK. Esophageal perforation. A reassessment of the criteria for choosing medical or surgical therapy. Arch Int Med 1992; 152: 757-6I

4 Lyons SL, Seremetis MG, deGuzman VC, Peabody JW. Ruptures and perforations of the esophagus: the case for conservative management. Ann Thoracic Surg 1978; 25: 344-50

5 Triggiani E, Belsey R. Oesophageal trauma: incidence, diagnosis, and management. Thorax 1977; $32: 241-49$

\title{
Coronary artery spasm and non-Q-wave myocardial infarction following intravenous ephedrine in two healthy women under spinal anaesthesia
}

\author{
A. Wahl' ${ }^{1}$, F. R. Eberli ${ }^{1}$, D. A. Thomson ${ }^{2}$ and M. Luginbühl ${ }^{2 *}$ \\ ${ }^{I}$ Cardiology, Swiss Cardiovascular Centre and ${ }^{2}$ Department of Anaesthesiology, University Hospital of \\ Bern, CH-3010 Bern, Switzerland \\ *Corresponding author
}

\begin{abstract}
Vasovagal episodes occur frequently in young healthy patients undergoing venous cannulation and loco-regional anaesthesia. We report two cases of severe coronary vasospasm and non-Qwave infarction in healthy young women after administration of ephedrine for vasovagal
\end{abstract}


symptoms at the onset of spinal anaesthesia. In the light of unopposed vagal predominance predisposing patients to coronary vasospasm, even in young healthy patients, atrophine and not ephedrine should be the first line treatment for bradycardia with or without hypotension under spinal anaesthesia.

BrJ Anaesth 2002; 88: 519-23

Keywords: agonists, adrenergic; complications, hypertension; heart, arrhythmia, tachycardia; spinal cord, sensory block; veins, complications

Accepted for publication: May 14, 2002

Vasovagal reactions may occur in $10 \%$ of patients, and have an even higher incidence in patients under $40 \mathrm{yr}$ of age and in those with a prior history. ${ }^{1}$ Vasovagal syncope induced by anaesthetic interventions may occur in 1 in 5000 cases. $^{2}$ Vagal predominance is considered to be an important risk factor for the development of severe bradycardia or asystole during spinal anaesthesia, ${ }^{3}$ and it may also induce multivessel coronary vasospasm that resolves after administration of atropine. ${ }^{4}$ To prevent asystole, Pollard ${ }^{3}$ suggests a stepwise treatment for bradycardia under spinal anaesthesia using atropine, ephedrine and then epinephrine, whereas Kinsella and Tuckey ${ }^{5}$ consider ephedrine as the most logical treatment. Ephedrine or related alkaloids have induced coronary artery spasms with or without myocardial infarctions in several cases, ${ }^{6-12}$ some of them fatal. Three other cases were related to administration of ephedrine in the context of regional anaesthesia, ${ }^{13-15}$ all of them in male subjects of more than $40 \mathrm{yr}$, one of whom had a history of cocaine abuse.

We describe two cases of coronary artery spasm induced by ephedrine given for treatment of a vasovagal reaction at the placement of a spinal anaesthetic in young women who had minimal cardiovascular risk factors and angiographically normal coronary arteries.

\section{Case 1}

A 26-yr-old athletic female (height, $169 \mathrm{~cm}$; weight, $72 \mathrm{~kg}$ ) was scheduled for pelvic osteotomy under combined spinal-epidural anaesthesia. She admitted to smoking (four cigarettes month ${ }^{-1}$ ) but otherwise she had no risk factors for cardiovascular disease. After oral premedication with $7.5 \mathrm{mg}$ of midazolam and an i.v. injection of $50 \mu \mathrm{g}$ of fentanyl to this slightly nervous patient, the epidural space was located with an 18-gauge Tuohy needle in the third lumbar interspace with the patient in the sitting position. Thereafter, $20 \mathrm{mg}$ of plain bupivacaine was injected intrathecally after dural puncture with a 27-gauge Pencan $^{\text {TM }}$ needle (Braun, Melsungen, Germany) through the epidural needle. During subsequent placement of the epidural catheter for postoperative analgesia, the patient complained suddenly of nausea and dizziness, while the patient's arterial pressure decreased from $145 / 85$ to $125 / 50$ $\mathrm{mm} \mathrm{Hg}$ and her heart rate from 80 to 55 beats $\mathrm{min}^{-1}$.
Presuming a rapidly increasing level of spinal block and aiming at completing the fixation of the inserted epidural catheter in the sitting patient, $10 \mathrm{mg}$ of ephedrine followed by $0.5 \mathrm{mg}$ of atropine and another $10 \mathrm{mg}$ of ephedrine were given intravenously within a few minutes. Then the patient was placed supine. Shortly afterwards, ECG monitoring showed a non-sustained wide complex regular rhythm at a rate of 150 beats $\mathrm{min}^{-1}$ consistent with ventricular tachycardia, followed by sinus tachycardia at 195 beats $\mathrm{min}^{-1}$, ST-segment elevation and arterial hypertension (215/ $150 \mathrm{~mm} \mathrm{Hg}$ ). The patient complained of chest pain and dyspnoea, although her heart rate and arterial pressure returned to normal within 5-10 min. Immediately after this event, the level of spinal anaesthesia was at T8. Surgery was cancelled, and the patient taken to the postanaesthesia care unit for cardiology consultation.

The ECG $1 \mathrm{~h}$ after the event showed diffuse ST-segment depression, and transthoracic echocardiography revealed a moderately-to-severely impaired left ventricular systolic function (ejection fraction $40 \%$ ), with mild mitral regurgitation, akinesia of the basal segments and apical hypercontractility. The ECG had returned to normal $8 \mathrm{~h}$ later, whereas the troponin-I concentration rose from $4.7 \mu \mathrm{g} \mathrm{litre}^{-1}$ (2.5 $\mathrm{h}$ after the event) to a peak of $29.5 \mu \mathrm{g}$ litre $^{-1} 8 \mathrm{~h}$ later (normal range $<0.6$ ). Total $\mathrm{CK}$ and CK-MB mass peaked at 268 units litre ${ }^{-1}$ (normal range $<167$ ) and $18.9 \mu \mathrm{g}$ litre $^{-1}$ (normal range $<4.0$ ), respectively, $11 \mathrm{~h}$ after the event, consistent with non-Q-wave myocardial infarction. Coronary angiography performed the next day revealed normal coronary arteries. Global left ventricular systolic function was normal (EF 64\%), but hypokinesia of the anterobasal, inferobasal and lateral wall segments was noted, and left ventricular end diastolic pressure was increased (22 $\mathrm{mm} \mathrm{Hg}$ ). An echocardiography performed on the 4th day showed normalization of left ventricular systolic function, with a small pericardial effusion. The patient underwent uneventful surgery under general anaesthesia 3 months later.

\section{Case 2}

A 34-yr-old female (height, $163 \mathrm{~cm}$; weight, $66 \mathrm{~kg}$ ) with a history of smoking ( 7 pack-years) and a family history of coronary artery disease, was scheduled for left hip 
arthrotomy under combined spinal-epidural anaesthesia. She had experienced a vasovagal syncopal episode during blood donation, and had undergone prior uneventful spinal anaesthesia for knee arthroscopy $2 \mathrm{yr}$ earlier. Thirty minutes after oral premedication with $7.5 \mathrm{mg}$ of midazolam, the obviously anxious patient was monitored with ECG, noninvasive arterial pressure and pulse oximetry. A 14-gauge i.v. cannula was inserted under local anaesthesia. After injection of $50 \mu \mathrm{g}$ of fentanyl intravenously, the patient was moved to the sitting position for epidural puncture, when she suddenly complained of nausea and dizziness. The patient was immediately placed supine and felt better. She was then turned to the right lateral position and again complained of nausea and was pale and bradycardic (38 beats $\min ^{-1}$ ). Two doses of ephedrine $5 \mathrm{mg}$ were administered intravenously together with $500 \mathrm{ml}$ of lactated Ringer's solution both to treat the bradycardia and to provide prophylaxis against the expected sympathetic block with spinal anaesthesia. The subsequent dural puncture in the third lumbar interspace, intrathecal injection of $20 \mathrm{mg}$ bupivacaine and placement of the epidural catheter were uneventful. The intravascular position of the catheter was excluded by injection of $3 \mathrm{ml}$ of $2 \%$ mepivacaine with epinephrine $5 \mu \mathrm{g} \mathrm{ml}^{-1}$ after a negative aspiration test. The patient was turned to the supine position for placement of a Foley catheter and an additional $500 \mathrm{ml}$ of pentastarch was infused. Ten minutes later a sensory level of T3 was reached without a significant decrease of arterial pressure or heart rate. The patient was again turned to the right lateral position for surgery. Immediately afterwards she became pale, dizzy and nauseated, her arterial pressure decreased from $110 / 65$ to $75 / 40 \mathrm{~mm} \mathrm{Hg}$ and her heart rate from 70 to 35 beats $\mathrm{min}^{-1}$. Aiming at correcting both heart rate and arterial pressure three $5 \mathrm{mg}$ boluses of ephedrine were injected, which was followed by a non-sustained wide complex regular rhythm at 150 beats min $^{-1}$ consistent with ventricular tachycardia, spontaneously converting to sinus tachycardia at 170 beats min $^{-1}$ with ST-segment elevation. At that time the patient was hypertensive $(230 / 135 \mathrm{~mm} \mathrm{Hg})$, and showed progressive desaturation to $90 \%$ associated with crackles on auscultation of the depending right chest, chest pain, dyspnoea and headache. At this stage a total of 1000 $\mathrm{ml}$ of lactated Ringer's solution and $500 \mathrm{ml}$ of pentastarch had been infused. Her heart rate and arterial pressure returned to normal within $5 \mathrm{~min}$ but oxygen saturation did not improve significantly during the subsequent $15 \mathrm{~min}$. Surgery was cancelled and the patient moved to the post anaesthesia care unit.

The ECG $90 \mathrm{~min}$ after the event showed ST-segment depression in V3 and V4, but the chest $\mathrm{x}$ ray showed cardiomegaly and right-sided pulmonary oedema. Echocardiography revealed a slightly diminished left ventricular systolic function (EF 55\%), with akinesia of the basal segments and apical hypercontractility, and moderate mitral regurgitation. Troponin-I and total CK concentration peaked at $25.8 \mu \mathrm{g} \mathrm{litre}^{-1}$ and 185 units $^{-1}$, respectively, $10 \mathrm{~h}$ after the event, consistent with minimal non-Q-wave myocardial infarction. Coronary angiography performed the next day revealed normal coronary arteries. The left ventricular systolic function was slightly depressed (EF 50\%) with hypokinesia of the anterobasal, inferobasal and lateral wall segments, and the left ventricular end diastolic pressure was increased $(22 \mathrm{~mm} \mathrm{Hg})$. An echocardiography performed on the 4th day showed normalization of left ventricular systolic function, with only minimal mitral regurgitation. The patient underwent uneventful surgery under general anaesthesia 3 months later. The correct ephedrine concentration was confirmed by the hospital pharmacy in the remainder of the liquid from the 'ephedrine syringe' used in this patient and the possibility of contamination with other substances was excluded.

\section{Discussion}

We observed two cases of chest pain, dyspnoea, nonsustained ventricular tachycardia, ST segment depression, non-Q-wave infarction and extended myocardial stunning occurring immediately after i.v. administration of ephedrine to treat symptomatic hypotension and bradycardia, after induction of spinal anaesthesia in two young women with angiographically normal coronary arteries. Both patients presented with vagal symptoms prior to the administration of the neuraxial block.

In Case 1 the sitting position was maintained for a few minutes in order to complete epidural catheter fixation despite the patient's complaint of nausea and dizziness. The decrease of heart rate and arterial pressure was aggressively treated with ephedrine assuming a rapidly increasing level of spinal block. However, the level of the block recorded immediately after the event was only T8. She was not hypotensive and only slightly bradycardic at the onset of symptoms, although her heart rate decrease from 80 to 55 beats $\min ^{-1}$ was abrupt. Many of the reported cases of asystole under spinal anaesthesia occurred within seconds of the abrupt onset of bradycardia, suggesting a cardiac reflex induced by an acute drop in right-sided cardiac filling pressure. ${ }^{1617}$ Because of this and another case report, ${ }^{18}$ the early use of ephedrine is recommended ('treat the downward trend') in our department. In retrospect this patient's symptoms were more likely to have been vasovagal in origin and the dose of ephedrine excessive. The use of the sitting position for easier siting of combined spinal-epidural analgesia may have further increased the risk of a vasovagal episode. $^{5}$

In Case 2, a clearly anxious patient with a history of vasovagal syncope and some vasovagal reaction even before the start of the procedure, exhibited a rather high level of spinal block that was well tolerated until she was turned to a lateral position. In contrast to the first patient, she was administered a larger volume of i.v. fluid and kept in the right lateral position for at least $15 \mathrm{~min}$ after the onset of 
symptoms. This explains why the subsequent pulmonary oedema was predominantly on the right side. As in the first patient the initial symptoms of fainting were treated first with ephedrine and not atropine. Nevertheless, the patient developed severe bradycardia and hypotension on moving her from the supine to the right lateral position.

We can only speculate as to the pathophysiological mechanism causing myocardial ischaemia, diastolic dysfunction, pulmonary oedema and infarction associated with the transient regional left ventricular dysfunction. A predominant vagal tone, as occurred in both of our patients, may induce multivessel coronary vasospasm. ${ }^{4} \mathrm{~A}$ decreased sympathetic tone caused ST-segment depression in women during Caesarean section under spinal anaesthesia. ${ }^{19}$ Intracoronary injection of acetylcholine is used as a diagnostic test to identify patients with coronary artery spasm, which supports the pathogenic role of predominant vagal tone. ${ }^{2021}$ In a recent study on dobutamine stress echocardiography ${ }^{22}$ the pure $\beta$-stimulator, dobutamine, induced coronary vasospasm in patients with coronary spastic angina inducible by intracoronary acetylcholine.

Other explanations are less likely. Myocardial ischaemia secondary to a massively increased oxygen demand associated with sinus tachycardia and severe hypertension after administration of atropine and ephedrine is unlikely. In young patients with excellent exercise tolerance and angiographically normal coronary arteries, such periods of hypertension, even when preceded by hypotension, are usually well tolerated and have not been reported to be associated with regional wall abnormalities. Even less likely as an explanation would be acute thrombus formation in normal coronary arteries with spontaneous lysis, since the regional distribution of the stunned myocardium would require several coronary arteries to be affected.

Anaesthetists are more and more reluctant to use vagolytic drugs prophylactically, in order not to mask the tachycardia induced by accidental i.v. injection of an epinephrine-containing test dose, and also because the tachycardia induced by atropine is considered potentially harmful in elderly patients. Moreover vasovagal syncope occurring during placement of i.v. lines or regional blocks is considered a harmless and mostly spontaneously resolving event. Vasovagal fainting is associated with an increased vagal, and a decreased sympathetic, activity explaining bradycardia and hypotension, respectively. ${ }^{5}$ Kinsella and Tuckey ${ }^{5}$ therefore suggest ephedrine as the logical first-line drug treatment of bradycardia during spinal anaesthesia, whereas others recommend atropine first and then ephedrine. $^{3}$

In order to prevent fatal cardiac arrest under spinal anaesthesia early aggressive treatment of bradycardia and hypotension with fluids, atropine, ephedrine and eventually epinephrine is recommended. How early, at what dose and what intervals the drugs are to be administered must be decided by the attending anaesthetist. Whereas administer- ing 'too little, too late' may lead to asystole, 'too much, too early' may lead to arrhythmia and coronary vasospasm with infarction, as in our two cases. Furthermore, although the ephedrine doses as administered in our patients seem to be large, similar doses were investigated for prophylactic use without serious side effects. ${ }^{23} 24$

The important parasympathetic predominance in two young, anxious women may have increased the risk for coronary vasospasm that was then induced by, retrospectively, too large a dose of ephedrine, administered under the assumption of a rapidly increasing level of spinal block. Prior administration of atropine, especially to the first patient who was not hypotensive at the onset of the symptoms, might have prevented the coronary vasospasm.

We conclude that a delay of immediate supine placement of a patient suffering from vasovagal symptoms during placement of neuraxial block in the sitting position may not be compensated by increasing the dose of $\alpha$ - and $\beta$ adrenergic drugs. In the light of unopposed vagal predominance predisposing to coronary vasospasm, even in young healthy patients, the previously suggested sequence of first injecting atropine and then ephedrine in the case of bradycardia with or without hypotension under spinal anaesthesia is further corroborated.

\section{Acknowledgement}

This work was funded by the research funds of the Cardiology and Anaesthesia Department, University Hospital of Bern, Switzerland.

\section{References}

I Pavlin DJ, Links S, Rapp SE, Nessly ML, Keyes HJ. Vaso-vagal reactions in an ambulatory surgery center. Anesth Analg 1993; 76: 931-5

2 Hosie L, Wood JP, Thomas AN. Vasovagal syncope and anaesthetic practice. Eur J Anaesthesiol 200I; 18: 554-7

3 Pollard JB. Cardiac arrest during spinal anesthesia: common mechanisms and strategies for prevention. Anesth Analg 2001; 92 : 252-6

4 Osborn LA, Reynolds B. Vagally mediated multivessel coronary artery spasm during coronary angiography. Cathet Cardiovasc Diagn 1998; 44: 423-6

5 Kinsella SM, Tuckey JP. Perioperative bradycardia and asystole: relationship to vasovagal syncope and the Bezold-Jarisch reflex. $\mathrm{Br}$ J Anaesth 2001; 86: 859-68

6 Wiener I, Tilkian AG, Palazzolo M. Coronary artery spasm and myocardial infarction in a patient with normal coronary arteries: temporal relationship to pseudoephedrine ingestion. Cathet Cardiovasc Diagn 1990; 20: 51-3

7 Derreza H, Fine MD, Sadaniantz A. Acute myocardial infarction after use of pseudoephedrine for sinus congestion. J Am Board Fam Pract 1997; 10: 436-8

8 Cockings JG, Brown $M$. Ephedrine abuse causing acute myocardial infarction. Med J Aust 1997; 167: 199-200

9 Theoharides TC. Sudden death of a healthy college student related to ephedrine toxicity from a ma huang-containing drink [letter]. J Clin Psychopharmacol 1997; 17 : 437-9

10 Franklin QJ. Sudden death after typhoid and Japanese encephalitis 
vaccination in a young male taking pseudoephedrine. Mil Med 1999; 164: 157-9

II Adverse events associated with ephedrine-containing products-Texas, December 1993-September 1995. Morb Mortal Wkly Rep 1996; 45: 689-93

12 Josefson D. Herbal stimulant causes US deaths. Br Med J 1996; 312: 1378-9

13 Lustik SJ, Chhibber AK, van Vliet M, Pomerantz RM. Ephedrineinduced coronary artery vasospasm in a patient with prior cocaine use. Anesth Analg 1997; 84: 931-3

14 Hirabayashi $Y$, Saitoh K, Fukuda H, Mitsuhata H, Shimizu R. Coronary artery spasm after ephedrine in a patient with high spinal anesthesia. Anesthesiology 1996; 84: 22I-4

I5 Imamura M, Matsukawa T, Kashimoto S, Nonaka A, Kumazawa T. A case of coronary artery spasm during spinal anesthesia. J Clin Anesth 1996; 8: 522-4

16 Lovstad RZ, Granhus G, Hetland S. Bradycardia and asystolic cardiac arrest during spinal anaesthesia: a report of five cases. Acta Anaesthesiol Scand 2000; 44: 48-52

17 Geffin B, Shapiro L. Sinus bradycardia and asystole during spinal and epidural anesthesia: a report of 13 cases. J Clin Anesth 1998; 10: $278-85$

18 Bailey PL. Sinus arrest induced by trivial nasal stimulation during alfentanil-nitrous oxide anaesthesia. Br JAnaesth 1990; 65: 718-20
I9 Eisenach JC, Tuttle R, Stein A. Is ST segment depression of the electrocardiogram during cesarean section merely due to cardiac sympathetic block? Anesth Analg 1994; 78: 287-92

20 Goto $A$, Ito $S$, Kondo $H$, et al. Evaluation of adjunctive intracoronary administration of acetylcholine following intravenous infusion of ergonovine to provoke coronary artery spasm. J Cardiol 1999; 34: 309-16

21 Sueda $\mathrm{S}$, Ochi $\mathrm{N}$, Kawada $\mathrm{H}$, et al. Frequency of provoked coronary vasospasm in patients undergoing coronary arteriography with spasm provocation test of acetylcholine. Am J Cardiol 1999; 83: 1186-90

22 Kawano $H$, Fujii $H$, Motoyama $T$, Kugiyama $K$, Ogawa $H$, Yasue $\mathrm{H}$. Myocardial ischemia due to coronary artery spasm during dobutamine stress echocardiography. Am J Cardiol 2000; 85: 26-30

23 Kee WD, Khaw KS, Lee BB, Lau TK, Gin T. A dose-response study of prophylactic intravenous ephedrine for the prevention of hypotension during spinal anesthesia for cesarean delivery. Anesth Analg 2000; 90: 1390-5

24 Chan WS, Irwin MG, Tong WN, Lam YH. Prevention of hypotension during spinal anaesthesia for caesarean section: ephedrine infusion versus fluid preload. Anaesthesia 1997; 52: 908-13 